\title{
Computational and experimental investigation into mechanical performances of Poly-L-Lactide Acid (PLLA) coronary stents
}

\author{
Qian Wang ${ }^{1}$, Gang Fang ${ }^{1,2}{ }^{*}$, Yinghong Zhao ${ }^{3}$, Guohui Wang ${ }^{3}$, Tao Cai ${ }^{3}$ \\ ${ }^{1}$ Department of Mechanical Engineering, Tsinghua University, 100084, Beijing, China \\ ${ }^{2}$ State Key Lab of Tribology, 100084, Beijing, China \\ ${ }^{3}$ Shanghai Bio-heart Biological Technology Co., Ltd., Suite 302, Building 9, 590 Ruiqing Rd, \\ 201201, Shanghai, China \\ *Corresponding author, Gang Fang: Tel: +86-10-6278 2694, E-mail: fangg@tsinghua.edu.cn
}

\begin{abstract}
Poly-L-lactide Acid (PLLA), as a credible biodegradable polymer-based material, can provide a promising amount of degradation time for vessel remodeling. Served as a sort of reliable intravascular implants, PLLA stents are expected to provide sufficient scaffolding to the target arteries without generating too much recoil after deployment. Besides, the stress and strain distribution should be as homogeneous as possible, and the stent conformability in fitting to the nature curvature of the vessels needs to be guaranteed. In the present study, mechanical performances of a stent made of PLLA material were investigated based on 3-D finite element method (FEM) and experiment verification. Simulations contained four deformation steps: crimping, spring-back after crimping, expanding and spring-back after expanding. The stent's deformation and stress/strain generation were analyzed. Several indexes including radial recoil ratio after crimping and expanding to different sizes, radial properties including radial strength, radial stiffness and collapse pressure were established. In vitro experiments
\end{abstract}


of the stent were conducted as the verification of the FEM results, and a good agreement between them was obtained. Moreover, simulation of three-point bending was performed to assess the bending flexibility of the stent, and bending stiffness was defined as a measurement of structure resistance to the bending deformation.

Keywords: biodegradable stent, PLLA, finite element simulation, radial property, bending flexibility

\section{Introduction}

At present, the majority of intravascular stents are made of permanent (nondegradable) metal materials such as stainless steel (316L), cobalt-chromium alloy and nickel-titanium alloy, etc. The permanent metallic materials have fairly good biocompatible and mechanical properties, so the stents made of those materials can experience great deformation in the transformation process and supply sufficient scaffolding to the target arteries [1]. Nevertheless, some drawbacks are recognized. According to the clinical follow-up observations, after stent's implantation, there is a period of 6-12 months for the arterial vessel remodeling process to be completed [2-4]. Then the arterial tissue finds a new equilibrium after having been stressed by deployment of the stent, and the implanted stent becomes unnecessary[2]. The permanent stent remains in the patients' arteries, which causes great risk of loosening, fracturing, tissue inflammation, in-stent restenosis and thrombosis[5]. In this opportunity, the biodegradable stent is proposed as an efficient alternative solution. Current candidate biodegradable materials are magnesium based alloys, pure iron and 
iron based alloys, and biodegradable polymer-based materials[2]. As the time develops after implantation, the biodegradable material stent's structure is gradually eroded by the body fluid until dissolving completely, without causing long term mechanical injury to the inner wall of the arteries. An ideal stent is supposed to keep its mostly mechanical integrity during the vessel remodeling process, thereafter begin a quick biodegradation. It is optimal for a stent to biodegrade over a total period of 12-24 months [6]. In fact, the biodegradable metallic materials have preferable mechanical properties than polymers, but polymers seem to provide the more suitable degradation time. Bartkowiak-Jowsa et al. [7] studied the degradation behaviors of three kinds of polymers: PLLA, PGLA and PDGLA. It was reported that it took approximately 24 months for PLLA to degrade completely, which was a much more promising time span than magnesium based alloys and other two polymer-based materials (PGLA and PDGLA). As for magnesium based alloys and iron based alloys, the former degrades too fast and the latter is expected to accelerate its degradation. A biodegradable Magnesium stent was used to rescue a pre-term baby with left lung reperfusion: the stent completely disappeared after 3 months[8]. Pure iron stents were applied in the descending aorta of New Zealand rabbits up to 18 months, resulting that accelerated degradation was warranted [9].

Lots of safety concerns need to be checked when determining the applicability of regulatory limitations prior to use intravascular implants. While a vascular stent is considered to serve in the clinical application, mechanical performances need to be evaluated by experimental and computational tests. Because of the difficulty and 
time-consuming of physical tests, finite element method (FEM) becomes an alternative choice to effectively solve the problem. In the published reports, various ways to examine the stent's mechanical properties were tested out. Li et al. [10] set up a 3-D model of magnesium alloy stent including stent ring, crimping and expanding rigid cylinders to compare the differences of a common stent design with its optimized shape in max principal stain after expansion, crimping recoil, expanding recoil, residual stress and radial strength. In their study, the pressure required for $10 \%$ diameter loss in crimping step was defined as the radial strength[10]. Imani et al. [11] gave a more detailed 3-D model which contained the stent, artery with plaque, and a balloon modeled by polyurethane rubber, then the dog boning and restenosis rate were evaluated by the stent's and artery's performance. Welch et al. [12] characterized the balloon-induced fiber deformation and unfurling of an internally polymer fiber stent, and compared the model-predicted permanent plastic deformation with SEM images of the fiber twist from the same region. Debusschere et al. [13] investigated the influence of the expansion rate on the mechanical performance and integrity of the deployed biodegradable polymeric stent. In their FEM model, the stent and the folded balloon were concerned to conduct the free expansion process.

In the present study, we investigated the mechanical performances of a stent made of PLLA material based on 3-D FEM models. In vitro experiments of stent's deformation were settled as the verification of the FE modeling. Moreover, simulation of three-point bending was performed to assess the stent bending flexibility. 


\section{Preparation of FEM models and verification experiment}

In this study, two FEM models were built to investigate the stent's mechanical deformation through ABAQUS/Standard implicit solver. The radial strength and the bending flexibility of the PLLA stent were evaluated on based of the American Society for Testing and Materials (ASTM) standard. In vitro experiments were arranged to reproduce the deformation processes of the stent, which were compared with the simulation results.

\subsection{Geometry models and boundary conditions}

The geometry model of the PLLA stent is shown in Error! Reference source not

found.. The stent is constructed with an outer diameter of $3.40 \mathrm{~mm}$, a thickness of $0.15 \mathrm{~mm}$, presenting six peak-to-valley struts in the circular direction. The stent's configuration consists two forms of struts, one is circular curve (CC) with a width of $0.20 \mathrm{~mm}$ which forms the hoop stent ring, and another one is straight line (SL) with a width of $0.18 \mathrm{~mm}$ that connects the adjacent rings with three SL struts distributing in every $120^{\circ}$.

Considering the repetition of the stent ring geometry in the axial direction, two adjacent rings (length: $1.92 \mathrm{~mm}$ ) were taken out for modeling of mechanical deformation and evaluations for radial strength. The model of three-point bending adopted nineteen interlaced rings (length: $18.0 \mathrm{~mm}$ ). The stent's structures were both meshed by hexahedral reduced integrated element (C3D8R). The effect of grid size on 
simulation results was analyzed and the discretization solution was determined: the stent was meshed with four layers of grids in wall thickness (Fig. 2) and the grid shape was adjusted close to cube. Structure with two rings for radial strength simulation was meshed to 24808 elements. The whole stent for bending simulation was meshed to 173968 elements.

In the simulation, the crimper and the expander were both featured as cylindrical surfaces, whose diameters were $4.0 \mathrm{~mm}$ and $0.5 \mathrm{~mm}$, respectively. The assembly model including the stent rings, the crimper and the expander is shown in Error! Reference source not found.. In most of reported researches, the crimping process was accomplished by the radial shrink of the applied rigid cylindrical surface. Three possible ways were reported to simulate the expansion of balloon-expandable stents: 1) neglecting the presence of the balloon, 2) assuming the balloon as a cylindrical shape or 3) taking the actual folded shape of the balloon into account[14]. Takashima et al. [15] assumed a cylindrical balloon catheter with great stiffness to expand the stent by controlling the radial direction displacement. The FE results (except for the contact area ratio) were validated both qualitatively and quantitatively.

The crimper and the expander were controlled by given radial displacements. One end of the stent rings was fixed in the axial direction, and another end was free. The straight lines (SL) were free only in the axial direction. The interactions between the crimper and the outer surface of the stent rings were assumed as isotropic with a friction coefficient of 0.15 . The same conditions were defined for the contact between the expander and the inner surface of the stent rings. The self-contact of the stent rings 
was defined and the frictionless condition was supposed.

Schematic of three-point bending apparatus is shown in Error! Reference source

not found.. Two lower static supports were displaced in a selected span according to the stent's length. The upper load applicator sat in the middle point of the span. As the upper load applicator driven by the mechanical test system crosshead moved down and forced the tested stent to bend. Once the displacement of the upper load applicator reached the pre-set value, it would move up and unload. During the contacting, the force and displacement of upper load applicator were recorded.

In the model of three-point bending (Error! Reference source not found.), two lower static supports and one upper load applicator were all modeled as the parallel rigid cylinders with a diameter of $6.35 \mathrm{~mm}$ according to ASTM F2606-08 [16]. When the stent length is $18 \mathrm{~mm}$, the suggested span length is $11 \mathrm{~mm}$, and no more deflection than $2.2 \mathrm{~mm}$ is allowed in this span [16].

\subsection{Material Properties}

Poly-L-lactide Acid (PLLA) was chosen as the stent material in the present study. The original PLLA tubes were extruded from synthetic homo-polymer, which was semi-crystalline with the number-average molecular weight of $200000 \sim 250000$. The crimping and the expanding were conducted at $48^{\circ} \mathrm{C}$ and $37^{\circ} \mathrm{C}$, respectively. The stent was crimped at $48^{\circ} \mathrm{C}$ to ensure enough deformability, then expanded at $37^{\circ} \mathrm{C}$ to imitate the temperature condition in human body. Therefore, it was necessary to prepare the constitutive data of PLLA at two exact temperatures. Besides, the 
evaluations for mechanical performances of PLLA stent were all done at $37^{\circ} \mathrm{C}$.

Uniaxial tensile tests of PLLA tube were conducted at $48^{\circ} \mathrm{C}$ and $37^{\circ} \mathrm{C}$, respectively. Test samples were cut from a whole extruded PLLA tube with an outer diameter of $1.6764 \mathrm{~mm}$ and an inner diameter of $0.6096 \mathrm{~mm}$. The gauge length of each sample of tension tests was $20 \mathrm{~mm}$. Under each test condition, at least four samples were used in case of the probability error. Tension tests were performed on universal material testing machine (AG-X, Shimadzu). The tensile speed was kept to $1 \mathrm{~mm} / \mathrm{min}$. Thermal-mechanical environment box was employed for temperature control. The temperature deviation was kept within $\pm 1^{\circ} \mathrm{C}$ during test procedure. DIC (Digital Image Correlation) optical measuring system[17] was applied to measure and record the deformation information. The PLLA tube samples are shown in Error! Reference source not found.. The PLLA micro tubes were cold mounted in two Polylactic Acid blocks at the ends for better tension clamping convenience.

The true stress-true strain curves of PLLA at $48^{\circ} \mathrm{C}$ and $37^{\circ} \mathrm{C}$ are shown in Error! Reference source not found., which embodied the typical tensile stress-strain response of materials with good plasticity. Once the yield stress was reached, a slight softening would arise, followed by the steady state of the stress corresponding the increasing strain. After necking, the strain on the surface of the tested PLLA tube could not be accurately measured by DIC. Moreover, the displacement of the crosshead was limited by the space of thermal-mechanical environment box equipped with temperature monitoring component. In these tensile tests, the elongation at material break was not acquired due to limitations mentioned above. Tension tests 
were stopped when the tensile force developed stably.

The material model used in the simulation had a density of $1.25 \mathrm{~g} / \mathrm{cm}^{3}$, a Young's modulus of $3.3 \mathrm{GPa}$ and a Poisson ratio of 0.3 . The yield stress at $37^{\circ} \mathrm{C}$ was $51.5 \mathrm{MPa}$ and close to the measurement results previously reported[18]). The yield stress of PLLA at $48^{\circ} \mathrm{C}$ was $44.5 \mathrm{MPa}$. The plastic property data (strain and stress) were provided on base of the experimental curves (Fig.6). The material was assumed as homogeneous and isotropic.

In the simulation of mechanical deformation and evaluation for radial strength, the crimper and the expander were both modeled as an isotropic elastic material with extremely high stiffness.

In the simulation of three-point bending, the lower static supports and the upper load applicator were all modeled as rigid material.

\subsection{Simulation setup of the stent mechanical deformation}

In the simulation of mechanical deformation, the simulation steps were set as: crimping (step 1), spring-back after crimping (step 2), expanding (step 3), and spring-back after expanding (step 4). At step 1, the crimper was driven by a displacement to shrink the stent with an outer diameter from $3.40 \mathrm{~mm}$ to $1.41 \mathrm{~mm}$, which was a similar scale that enables a pre-mounted stent to deliver in human vessels. Then the crimper was released to the initial size at step 2. For the stent, it recoiled after crimping. The temperature of the stent was set as $48^{\circ} \mathrm{C}$ in these two steps, which reproduced the real experimental conditions for improving the material plasticity 
during the in-vitro crimping process. So far, the simulation of the crimping process of the stent was completed.

At step 3, two alternative displacements were employed on the expander to expand the crimped stent separately to the inner diameter of $3.10 \mathrm{~mm}$ and $3.92 \mathrm{~mm}$. The PLLA stent configuration used in this study was aimed to ensure a nominal in-service inner diameter of $3.0 \mathrm{~mm}$. Considering the recoiling (spring-back) after the expanding, the excessive expanding displacement of $0.1 \mathrm{~mm}$ was set in the $\mathrm{FE}$ simulation. On the other hand, the inner diameter of $3.92 \mathrm{~mm}$ was set to investigate the limit expanding ability of the stent. Subsequently, the expander was released to the initial size at step 4. The last two steps simulated the stent's deployment in vivo after it was delivered in the vascular, and the stent temperature was set as $37^{\circ} \mathrm{C}$.

In summary, the simulation steps of mechanical deformation were arranged below, as shown in Error! Reference source not found..

Step 1: Crimped to an OD of $1.41 \mathrm{~mm}$ at $48^{\circ} \mathrm{C}$;

Step 2: Spring-back at $48^{\circ} \mathrm{C}$;

Step 3: Expanded to an ID of $3.92 \mathrm{~mm} / 3.1 \mathrm{~mm}$ at $37^{\circ} \mathrm{C}$;

Step 4: Spring-back at $37^{\circ} \mathrm{C}$.

\subsection{Simulation setup of the evaluation for stent radial strength}

The FE model for evaluating the radial strength of the stent was set, according to ASTM standard[19]. The radial strength, the radial stiffness and the collapse pressure represent the scaffolding ability of a stent implanted in the human arteries. Therefore, 
they have to be evaluated in the expanding state of the stent on base of the mechanical deformation where it was expanded to an inner diameter of $3.10 \mathrm{~mm}$.

Then two extra steps of displacement translation were defined on base of the expanded stent configuration, named radial strength evaluating process. In order to obtain the radial loading data sufficient for outputting various radial properties, the stent should be deformed severely enough. The deformation was certainly greater than that for clinical application. During the crimping process, the diameter of crimper was shrunk to $2.50 \mathrm{~mm}$, where the stent's outer diameter decreased $0.8 \mathrm{~mm}$. During the spring-back process, the crimper was gradually released, as shown in Error!

\section{Reference source not found..}

Simulation steps are arranged as:

Step 1 4: Mechanical deformation (crimped to $1.41 \mathrm{~mm}$ and expanded to

\section{$3.10 \mathrm{~mm}$ separately);}

Step 5: Crimped to an outer diameter of $2.50 \mathrm{~mm}$ at $37^{\circ} \mathrm{C}$;

Step 6: Spring-back at $37^{\circ} \mathrm{C}$.

The contact force and the stent's outer diameter during radial strength evaluating process (step 5 and step 6) were recorded, generating a radial loading curve of the PLLA stent.

\subsection{Simulation setup of evaluation for stent bending flexibility}

The three-point bending of the stent was simulated according to ASTM standard[16].

Two steps of the displacement of the upper load applicator were defined. In step 1 
(loading), a downward displacement $2.5 \mathrm{~mm}$ of the upper loading applicator was applied, and the corresponding deflection of the stent was $1.5 \mathrm{~mm}$. In step 2 (unloading), the upper loading applicator moved back to the initial position. Both steps were performed at $37^{\circ} \mathrm{C}$. The reactive force and displacement of the upper loading applicator were recorded during simulation, by which a bending force-deflection curve was generated. Simulation steps are arranged below, as shown in Error! Reference source not found.:

Step 1: Bending the stent to a deflection of $1.5 \mathrm{~mm}$ at $37^{\circ} \mathrm{C}$;

Step 2: Releasing at $37^{\circ} \mathrm{C}$.

\subsection{In vitro experiment conditions of stent deformation}

In order to investigate the deformation performance of PLLA coronary stent and verify the FEM simulation, the tests including crimping and expanding processes were conducted. In vitro mechanical deformation of the PLLA stent experiment was accomplished with the same setup parameters as the simulation. The stents under test had 19 interlaced peak-to-valley rings in the axial direction and was $18 \mathrm{~mm}$ long.

In vitro radial strength evaluation experiment was accomplished on the bench (Blockwise Radial Force Testing Equipment) at $37^{\circ} \mathrm{C}$. The loading steps and test conditions in the experiment, especially temperature, were kept the same as in the FE simulation. 


\section{Results and discussion}

\subsection{Mechanical deformation of the PLLA stent}

The mechanical deformation of the PLLA stent concentrated mainly at the peak and valley bows, extremely at the inside surface of a bow. As shown in Error! Reference source not found., the maximum value of the equivalent plastic strain reached 0.214 when the outer diameter of the stent was crimped to $2.60 \mathrm{~mm}$. The deformation concentrated in rather a small limited part of the bow.

Error! Reference source not found. shows the stent deformations resulted from FE simulation and in vitro experiments. Three key states of the stent were focused, which were corresponding to the crimped outer diameter of $2.60 \mathrm{~mm}, 1.80 \mathrm{~mm}$ and the final crimped profile, respectively.

In the crimping experiment of the stent, crazing, a distinctive phenomenon of macromolecular polymer when a certain degree of strain accumulated, appeared at these bows, as highlighted by red circles in Error! Reference source not found. (a) and (b), corresponding to the strain concentrating portions in the simulation. When the outer diameter of the stent was crimped to $2.60 \mathrm{~mm}$, the peak-to-valley struts seemed to shrink homogeneously in the circular direction. When the stent was crimped to the outer diameter of $1.80 \mathrm{~mm}$, the shrink in the circular direction was non-uniform anymore, and varied in adjoined rows of peak-to-valley struts. As shown in Error!

Reference source not found. (b), stent crimped much more obviously in the highlight yellow dash line row than in the blue solid line row. The same phenomena appeared in 
the simulation process. It was considered that the non-uniform geometry in the circular direction of the stent led to the non-uniform deformation. A peak-to-valley ring composes two repeating substructures with different stiffness: single circle part and circle part connected with straight link. The diverse stiffness of the substructures induced a prior deformation in one possible substructure and finally affected the deformation in the whole row.

The final crimped stent profile is shown in Error! Reference source not found. (c), and stent links were neat and no fracture happened.

During the expanding experiments, a series of deformation states were recorded to compare with the simulation results. Error! Reference source not found. lists the process of the stent expanding (OD increased from 3.19 to $4.22 \mathrm{~mm}$ ). The stent was expanded stably and homogenously, and no obvious fracture occurred during the whole process. When the outer diameter increased to $4.22 \mathrm{~mm}$, peak-valley-shaped rings of the stent were stretched nearly straight.

charactering stent's stiffness, was calculated in those deformation steps. Radial recoil ratio after crimping is defined by the profile changes between crimping and spring-back after crimping processes (Eq. 1). Spring-back after crimping causes the increase in the outer diameter which comes into being radial recoil ratio. Similarly, radial recoil ratio after expanding is defined by the shrink of inner diameter between expanding and spring-back after expanding processes (Eq. 2). The equations are listed below. 


$$
\begin{aligned}
& \text { Radial Recoil Ratio after Crimping }=\frac{\left|O D_{\text {crimp }}-O D_{\text {crimp recoil }}\right|}{O D_{\text {crimp }}} \\
& \text { Radial Recoil Ratio after Expanding }=\frac{\left|I D_{\text {expand }}-I D_{\text {expand recoil }}\right|}{I D_{\text {expand }}}
\end{aligned}
$$

Radial recoil ratio after expanding determines the over increment in the outer diameter of the stent applied in a particular vessel environment. Too much radial recoil brings out a large over-expanding and cause great strain generation in the arteries, leading to a great risk of mechanical injury and follow-up inflammation.

Radial recoil ratios of the crimped and expanded stent in simulation were calculated (Table 3). The outer diameter of the stent was recoiled to $1.56 \mathrm{~mm}$ after crimped to $1.41 \mathrm{~mm}$, resulting in a great radial recoil ratio of $10.87 \%$. For this stent structure, an over-crimping was necessary according to the clinical requirement. After crimping, the stent was expanded to different diameters. When the expanded inner diameter was $3.1 \mathrm{~mm}$, the radial recoil ratio was $4.19 \%$. The inner diameter was 2.97 mm after spring-back. As mentioned above, the used stent configuration was aimed to acquire a re-built vessel inner diameter of $3.0 \mathrm{~mm}$. Therefore, it was suggested that at least an over-expanding of $0.1 \mathrm{~mm}$ was required without taking the force induced by the stent-artery interaction into consideration. After expanded to the inner diameter of $3.70 \mathrm{~mm}$, the radial recoil ratio was $2.92 \%$, and when $3.92 \mathrm{~mm}$, it was $1.81 \%$. It could be found that the stent diameter recoiled less with the greater expanding amount. Meanwhile, the simulation results showed a good agreement with the experiment data. In vitro mechanical deformation experiment, when the stent was separately expanded to the inner diameters of $3.70 \mathrm{~mm}$ and $3.92 \mathrm{~mm}$, the radial recoils were around $2 \%$, 
and when expanded to inner diameter of $3.1 \mathrm{~mm}$, the radial recoil was $4.7 \%$.

Foreshortening is a significant index describing the length variation during stent's deployment[20]. On clinic, foreshortening shows a direct dimensional change in the axial direction between states of spring-back after crimping and expanding (eq. 3). Larger foreshortening will cause the greater mechanical injury of the artery.

$$
\text { Foreshortening }=\frac{l_{\text {crimp recoil }}-l_{\text {expand }}}{l_{\text {crimp recoil }}}
$$

In general, the stent foreshortening is greater than zero. In the present study, the compute value of $14.5 \%$ of the stent foreshortening was obtained when the stent was expanded to the inner diameter of $3.1 \mathrm{~mm}$. When the stent was expanded to the inner diameter of $3.92 \mathrm{~mm}$, the stent foreshortening was $25.9 \%$. The excessive foreshortening was mainly ascribed to the final straightening configuration of the peak-valley-shaped rings.

\subsection{Radial strength}

In the evaluation of the radial strength, when the crimper was engaged on the stent, it caused the contact force at the interface between the crimper and the stent's outer surface. The contact force was normalized by the initial stent deployed length (N/mm)[19], labeled as length normalized force (Eq. 4).

$$
\text { Length Normalized Force }=\frac{\text { Contact Force }}{\text { Initial Deployed Length }}
$$

Error! Reference source not found. shows the length normalized force versus the outer diameter of the crimped stent produced from radial strength evaluating 
process, named the radial loading curve. It was a complete cycle and could be divided into six segments: (A) initial loading; (B) linear loading; (C) plasticity increasing; (D) linear unloading; (E) final unloading; (F) return. It could be seen that at the incipient stage, the radial loading curve was non-linear Error! Reference source not found. (A)), when the crimper began to engage upon the stent during this period of crimping. When the crimper contacted with the stent steadily, the curve reached to be approximately linear Error! Reference source not found. (B)). In this stage, the stent underwent elastic deformation. The intercept of the linear fitting line of the loading curve with the $\mathrm{X}$-axis (diameter) was labeled as the zero compression diameter[19]. It acted as the equivalent initial outer diameter of the stent, and was used for the determination of radial properties. The zero compression diameter should be slightly smaller than the original outer diameter of the stent engaged before the radial strength evaluating process.

When the plastic deformation gradually accumulated, the loading curve started to be steady Error! Reference source not found. (C)). With the diameter decreasing, the normalized force grew by a slight and then declined slowly. Once the maximum compression reached, the unloading began. As shown in Error! Reference source not found. (D), the unloading curve was approximately linear, generating a linear fitting line almost with a same slope with loading curve. The difference in the intercept of $\mathrm{X}$-axis between the linear fitted loading curve and the linear fitted unloading curve reflected the diametric plastic deformation during the compression. Similar to the initial loading portion Error! Reference source not found. (A)), there 
was a significant non-linear portion at the end of unloading segment Error!

Reference source not found. (E)). The crimper gradually separated from the stent at this stage. Taking a specific amount of plastic deformation as a distinct point, the linear fitted unloading curve can be offset parallel by intercepting with $\mathrm{X}$-axis through it. Then the unloading offset line intersected loading line at a special point for radial strength determination.

Actually, the diacritical point has clinical significance. Stent migration and inadequate acute vessel patency may comprehensively influence the choosing of relevant diacritical point. According to the radial loading curve in Error! Reference source not found., the zero compression outer diameter of the engaged stent was 3.35 mm. In conjunction with stent design, the elastic recoil after expanding was suggested to be less than $4 \%[21]$. Taking $3 \%$ diameter loss as the label of diacritical point to compute the radial strength, the unloading offset equals $0.1 \mathrm{~mm}$. Thus unloading offset line was determined by the slope of linear fit line of unloading curve and the $\mathrm{X}$-axis intercept of $3.25 \mathrm{~mm}$. The intersect point of loading curve and unload offset line represents the radial strength of this PLLA stent, turning out $1.46 \mathrm{~N} / \mathrm{mm}$. The radial strength gained from in vitro radial force test was $1.55 \mathrm{~N} / \mathrm{mm}$ with the same unloading offset. It seems the simulation conservatively estimates the actual radial strength of the stent.

Radial strength represents the capacity to scaffold the narrowed vessel wall. The coronary stent is supposed to provide enough radial braced force to the vessel wall in a given diameter, otherwise lumen opening may not enough for blood re-flow and 
even cracks propagation and collapse will happen in the stent.

Schmidt et al. [22] suggested that the radial stiffness was determined from the profile decreasing in a physiological relevant range from 0.0 bar to 0.2 bar outer pressure (Eq. 5). The pressure at which the stent could no longer withstand the outer load was labeled as the collapse pressure. In this case, the output contact force was normalized by the instantaneous scaffolding area of the PLLA stent $(\mathrm{kPa})$. At the suggestion of ASTM F3067-14 [19], if using area normalized force, use the instantaneous stent diameter, instead of the starting diameter, multiplied by the initial expanded length (Eq. 6).

$$
\text { Radial Stiffness }=\frac{d(0 b a r)-d(0.2 b a r)}{d(0 b a r)} \rtimes 00 \%
$$

Area Normalized Force $=\frac{\text { Contact Force }}{p \rtimes \text { Instantaneous Diameter } \rtimes \text { Initial Deployed Length }}$

According to the present radial loading data, the radial stiffness is $1.40 \%$.

Because there was no obvious collapse in the stent during the whole deformation test, the pressure required for $10 \%$ diameter loss was labeled as collapse pressure in this study[23]. According to this method, it was predicted that the PLLA stent had a collapse pressure of $162 \mathrm{kPa}$.

Schmidt et al. [22] investigated the mechanical process of the stent implantation of nine kinds of different commercially available coronary stents, and acquired their profiles at different situations, elastic recoil, compliance, collapse pressure and radial stiffness and so on, as shown in Table 4. Nine kinds of stents were made of either Co-Cr alloys or stainless Steel (316L), and all of them had a nominal scaffolding 
inner diameter of $3.0 \mathrm{~mm}$. The experimental data showed that their relaxed inner diameter after expansion to nominal pressure (NP) varied from 2.7 to $2.9 \mathrm{~mm}$, and expanding radial recoil varied from $3.60 \%$ to $6.87 \%$. In this study, we calculated it as $4.19 \%$. Their collapse pressure between 0 to 0.2 bar varied from 130 to $245 \mathrm{kPa}$, and radial stiffness varied from $0.51 \%$ to $3.99 \%$. In our simulation, they were $162 \mathrm{kPa}$ and $1.40 \%$, respectively.

Li et al. [10] optimized the linear connecting links of the common magnesium biodegradable stent by FE simulations, and improved its collapse pressure from 147 to $151 \mathrm{kPa}$. Stack et al. [24] announced biodegradable stent named Duke stent and made from woven PLLA strands, and Duke stent was reported able to provide a collapse pressure of 100 to $130 \mathrm{kPa}$ [25]. Agrawal et al. [26] suggested a minimum collapse pressure of $0.04 \mathrm{MPa}$ for coronary stents. In general, the polymer biodegradable stent is considered undesirable in the mechanical behaviors due to the low Young's modulus and low yield strength. However, the present simulations predicted a sufficient collapse pressure larger than the minimum limit. Moreover, the stent under research showed a comparable radial recoil, radial stiffness and collapse pressure with other bare metal stent (BMS). The beneficial properties may result from slightly increase in stent dimension when compared to BMS.

\subsection{Flexibility property}

Three-point bending is an evaluation for stent's bending flexibility property, which affects the conformability of deployed stent. Theoretically, a stent with greater 
bending flexibility could better fit the natural curvature of the artery[16].

As shown in Error! Reference source not found., the force-deflection curve of three-point bending process could be divided into two segments: (A) loading, and (B) unloading. The loading curve was nonlinear and generated an elastic-plastic deformation. The unloading curve was keeping a proximately fixed offset to the loading curve, which indicated a certain amount of residual plastic deformation.

In the loading process, simulated equivalent plastic strain showed that the stent was bended with increasing elastic strain accumulation when the deflection was less than $0.85 \mathrm{~mm}$. The residual plastic strain distribution (Error! Reference source not found.) after three-point bending process showed that the strain concentrated in the connections of peak or valley portion with the axial link.

There isn't a recognized index to define the bending flexibility of a stent according to ASTM F2606-08[16]. However, by evaluation with the same fixed span, the bending flexibility of two or more test stents that differ in geometry designs or materials could be compared by the slopes of the force-deflection curves. The force-deflection curve with a steeper slope results the less bending flexibility of the stent. Moreover, the bending flexibility could be evaluated by comparison of the concentrated bending force between different stents, where the same fixed span length and given deflection are used. The stent with a lower bending force at the given deflection has the greater bending flexibility.

Schmidt et al. [27] considered the bending stiffness as the function of free bending length, deflection and bending force to evaluate the structure's resistance to 
bending deformation of a cantilever beam. In the present study, we suggest the calculation of the similar index used to build the bending stiffness of the stent as a simply supported beam. In the simplified model, the concentrated force was employed on the middle point of the beam. The bending stiffness EI (Eq. 7) was set as the function of the fixed span length $l$, deflection $f$ and concentrated bending force $F$. The bending stiffness of the PLLA stent at the deflection of $1.5 \mathrm{~mm}$ was $4.01 \mathrm{Nmm}^{2}$. A stent with a greater bending stiffness at a given deflection has the less bending flexibility.

$$
\text { Bending Stiffness } E I=\frac{F \times l^{3}}{48 f}
$$

If tests are performed with variable spans, the force-deflection curve ceases to be an effective method in comparing bending flexibility of different tests. Then the mid-span bending moment versus mid-span curvature takes the place to characteristic the bending flexibility. Similarly, a test stent with a lower slope of the result curve has the greater bending flexibility.

\subsection{Configuration and optimization}

The simulated stress distribution in the stent is shown in Error! Reference source not found. (a), where the high stress concentration can be seen in the waved ring corners. Distinct low stress pools could be found in regions of stress concentration. In order to homogenize the stress distribution, a simple partial structure optimization was proposed to the initial stent configuration. Basic zero-order methods employed to shape optimization are update rules based on engineering experience. For example, 
update rules adjust the boundary outward in high-stress regions and inward in low-stress regions[28]. Then a dimple was imposed at the convex side of each corner, resulting in a little mass loss to the whole stent. Moreover, the structure optimization homogenized the strain distribution and no distinct change was observed to other property indexes.

Luo et al. [29] investigated the degradation mechanism and behavior of PLLA bio-absorbable cardiovascular stents, and verified that the degradation speed of the structure was related to the initial strain value of the material prior to degradation, where the greater the initial strain level, the faster the degradation speed. It was found that the optimized stent not only homogenized the stress distribution, but also lower the max equivalent plastic strain. As shown in Error! Reference source not found., after crimped to the outer diameter of $2.2 \mathrm{~mm}$, the max equivalent plastic strain in the optimized configuration was 0.443 , less than which in the initial configuration $(0.452)$. Another significant change was the difference of the position where the max equivalent plastic strain was situated. The initial stent generated a maximum equivalent plastic strain (0.452) in location "B" as shown in Error! Reference source not found. (a), while in the same place of the optimized configuration, it resulted a much lower equivalent plastic strain of 0.375 (Error! Reference source not found. (b)). At the location "A" (Fig. 16) of the maximum equivalent plastic strain in the optimized configuration, the strain (0.443) was slightly higher than 0.433 in the initial stent.

Figs. 17 (a) and (b) showed the equivalent plastic strain distributions of the initial 
and optimized structures separately when the stent both finished spring-back after expanded to the inner diameter of $3.1 \mathrm{~mm}$. A slight decrease in the max equivalent plastic strain (2.975 to 2.730) was gained as a result of structural optimization.

\section{Conclusions}

The mechanical deformation of a PLLA biodegradable coronary stent were investigated through finite element simulations. Two significant properties of the stent, the radial scaffolding behavior and the bending flexibility, were evaluated.

Stress/strain distribution, radial recoil, radial strength, radial stiffness, collapse pressure, and bending stiffness were discussed. Compared with the in vitro experiment results, the simulation was proved to be reliable. Some key conclusions from this study can be drawn as:

1) Cold mounted in resin blocks, a Poly-L-lactide (PLLA) tube billet can be uniaxial tensioned, and the strain can be measured by digital image correlation (DIC) method with a high accuracy. In the present study, PLLA had a Young's modulus of $3.3 \mathrm{GPa}$, a yield strength of $44.5 \mathrm{MPa}$ at $48^{\circ} \mathrm{C}$ and $51.5 \mathrm{MPa}$ at $37^{\circ} \mathrm{C}$.

2) Finite element simulations of the stent's deformation had a good agreement with the experimental profiles. The stent was crimped non-uniformly in circular direction and had severe deformation in specific rows of peak-to-valley struts. Distinct low stress pools were found in local region of the stent. A local optimization for the stent was proposed and homogenized the stress distribution, and decreased the max equivalent plastic strain during mechanical deformation. 
3) The radial recoil of the stent was $4.19 \%$ when expanded to the ID of $3.1 \mathrm{~mm}$. In order to acquire the nominal scaffolding inner diameter of $3.0 \mathrm{~mm}$, a certain amount of over expanding was essential in clinical application. Foreshortening was $14.5 \%$ when expanded to the ID of $3.1 \mathrm{~mm}$.

4) A simulation for evaluating the radial strength of the stent was organized according to ASTM F3067-14 [19]. The calculated radial strength was 1.46 $\mathrm{N} / \mathrm{mm}$, and the corresponding measured value in vitro experiment was 1.55 $\mathrm{N} / \mathrm{mm}$. The radial stiffness was $1.40 \%$ and the collapse pressure was $162 \mathrm{kPa}$.

5) A simulation for evaluating the bending flexibility of the stent was organized on basis of ASTM F2606-08R14 [16]. The bending flexibility could be compared by the force-deflection curve through the same fixed span three-point bending test. Bending stiffness was defined and suggested as the measure index in evaluating the resistance to bending deformation. The bending stiffness of PLLA stent in the present study was $4.01 \mathrm{~N} / \mathrm{mm}^{2}$ at the deflection of $1.5 \mathrm{~mm}$ with the given span bending.

\section{Acknowledgments}

The authors greatly appreciate the financial support by Beijing Natural Science Foundation (No. 3142011) and the National Science Foundation of China (No. $51075230)$.

\section{References}


[1] Mani, G., M.D. Feldman, D. Patel, and C.M. Agrawal. 2007. Coronary stents: a materials perspective. Biomaterials 28:1689-1710.

10.1016/j.biomaterials.2006.11.042

[2] Hermawan, H., D. Dube, and D. Mantovani. 2010. Developments in metallic biodegradable stents. Acta Biomater. 6:1693-1697. 10.1016/j.actbio.2009.10.006

[3] Schmig, A., A. Kastrati, H. Mudra, R. Blasini, H. Schhlen, V. Klauss, G. Richardt, and F.J. Neumann. 1994. Four-year experience with Palmaz-Schatz stenting in coronary angioplasty complicated by dissection with threatened or present vessel closure. Circulation 90:2716-2724. http://dx.doi.org/10.1161/01.CIR.90.6.2716

[4] El-Omar, M.M., G. Dangas, I. Iakovou, and R. Mehran. 2001. Update on in-stent restenosis. Current interventional cardiology reports 3:296-305.

[5] Sillekens, W.H., and D. Bormann. 2012. 13 - Biomedical applications of magnesium alloys. Woodhead Publishing.

[6] Serruys, P.W., M.J. Kutryk, and A.T. Ong. 2006. Coronary-artery stents. New Engl. J. Med. 354:483-495. 10.1056/NEJMra051091

[7] Bartkowiak-Jowsa, M., R. Będziński, A. Kozłowska, J. Filipiak, and C. Pezowicz. 2013. Mechanical, rheological, fatigue, and degradation behavior of PLLA, PGLA and PDGLA as materials for vascular implants. Meccanica 48:721-731. $10.1007 / \mathrm{s} 11012-012-9626-2$

[8] Zartner, P., R. Cesnjevar, H. Singer, and M. Weyand. 2005. First successful implantation of a biodegradable metal stent into the left pulmonary artery of a preterm baby. Catheter. Cardio. Inte. 66:590-594. 10.1002/ccd.20520

[9] Peuster, M., P. Wohlsein, M. Brügmann, M. Ehlerding, K. Seidler, C. Fink, H. Brauer, A. Fischer, and G. Hausdorf. 2001. A novel approach to temporary stenting: degradable cardiovascular stents produced from corrodible metalresults $6-18$ months after implantation into New Zealand white rabbits. Heart 86:563-569. 10.1136/heart.86.5.563

[10] Li, J., F. Zheng, X. Qiu, P. Wan, L. Tan, and K. Yang. 2014. Finite element analyses for optimization design of biodegradable magnesium alloy stent. Materials Science and Engineering: C 42:705-714. 10.1016/j.msec.2014.05.078

[11] Imani, M., A.M. Goudarzi, D.D. Ganji, and A.L. Aghili. 2013. The comprehensive finite element model for stenting: The influence of stent design on the outcome after coronary stent placement. J. Theor. App. Mech.-Pol. 51:639-648.

[12] Welch, T., R.C. Eberhart, and C. Chuong. 2008. Characterizing the expansive deformation of a bioresorbable polymer fiber stent. Ann. Biomed. Eng. 36:742-751. 10.1007/s10439-008-9455-6 
[13] Debusschere, N., P. Segers, P. Dubruel, B. Verhegghe, and M. De Beule. 2015. A finite element strategy to investigate the free expansion behaviour of a biodegradable polymeric stent. J. Biomech. 48:2012-2018.

10.1016/j.jbiomech.2015.03.024

[14] De Beule, M. 2009. Chapter 2 - Biomechanical Modeling of Stents: Survey 1997 - 2007 A2 - Verdonck, Pascal, p. 61-93 Advances in Biomedical Engineering. Elsevier, Amsterdam. 10.1016/B978-0-444-53075-2.00002-2

[15] Takashima, K., T. Kitou, K. Mori, and K. Ikeuchi. 2007. Simulation and experimental observation of contact conditions between stents and artery models. Med. Eng. Phys. 29:326-335. 10.1016/j.medengphy.2006.04.003

[16] ASTM F2606-08,2014, Standard Guide for Three-Point Bending of Balloon Expandable Vascular Stents and Stent Systems, In A. International, (ed.), West Conshohocken, PA. http://dx.doi.org/10.1520/F2606

[17] Zhao, J., P. Zeng, L. Lei, and Y. Ma. 2012. Initial guess by improved population-based intelligent algorithms for large inter-frame deformation measurement using digital image correlation. Opt. Laser. Eng. 50:473-490. 10.1016/j.optlaseng.2011.10.005

[18] Paryab, N., D. Cronin, P. Lee-Sullivan, X. Ying, F.Y. Boey, and S. Venkatraman. 2012. Uniform expansion of a polymeric helical stent. Journal of Medical Devices 6:021012. 10.1115/1.4005777

[19] 2014. ASTM F3067-14 Guide for Radial Loading of Balloon Expandable and Self Expanding Vascular Stents, In A. International, (ed.), West Conshohocken, PA. http://dx.doi.org/10.1520/F3067-14

[20] Migliavacca, F., L. Petrini, M. Colombo, F. Auricchio, and R. Pietrabissa. 2002. Mechanical behavior of coronary stents investigated through the finite element method. J. Biomech. 35:803-811. 10.1016/S0021-9290(02)00033-7

[21] Sillekens, W.H., and D. Bormann. 2012. Biomedical applications of magnesium alloys, p. 427-452 Advances in wrought magnesium alloys. Woodhead Publishing.

[22] (ed.) 2009. World Congress on Medical Physics and Biomedical Engineering, September 7-12, 2009, Munich, Germany. Springer. 10.1007/978-3-642-03906-5_37

[23] Venkatraman, S., T.L. Poh, T. Vinalia, K.H. Mak, and F. Boey. 2003. Collapse pressures of biodegradable stents. Biomaterials 24:2105-2111. 10.1016/S0142-9612(02)00640-3

[24] Stack, R.S., R.M. Califf, H.R. Phillips, D.B. Pryor, P.J. Quigley, R.P. Bauman, J.E. Tcheng, and J.C. Greenfield. 1988. Interventional Cardiac Catheterization at Duke Medical Center-The Duke Interventional Cardiac Catheterization Program. Am. J. Cardiol. 62. 
[25] Gammon, R.S., G.D. Chapman, G.M. Agrawal, R.P. Bauman, H.R. Phillips, H.G. Clark, and R.S. Stack. 1991. Mechanical features of the Duke biodegradable intravascular stent. J. Am. Coll. Cardiol. 17:A235-A235.

10.1016/0735-1097(91)91907-V

[26] Agrawal, C.M., K.F. Haas, D.A. Leopold, and H.G. Clark. 1992. Evaluation of poly(L-lactic acid) as a material for intravascular polymeric stents. Biomaterials 13:176-82. 10.1016/0142-9612(92)90068-Y

[27] Schmidt, W., P. Lanzer, P. Behrens, L.D.T. Topoleski, and K.P. Schmitz. 2009. A Comparison of the Mechanical Performance Characteristics of Seven Drug-Eluting Stent Systems. Catheter. Cardio. Inte. 73:350-360. $10.1002 / \mathrm{ccd} .21832$

[28] Le, C., T. Bruns, and D. Tortorelli. 2011. A gradient-based, parameter-free approach to shape optimization. Comput. Method. Appl. M. 200:985-996. 10.1016/j.cma.2010.10.004

[29] Luo, Q., X. Liu, Z. Li, C. Huang, W. Zhang, J. Meng, Z. Chang, and Z. Hua. 2014. Degradation model of bioabsorbable cardiovascular stents. PLoS One 9:e110278. 10.1371/journal.pone.0110278 


\section{Figure captions:}

Fig. 1 PLLA stent (a) and geometry model (b) used for simulation and experiment (unit: $\mathrm{mm}$ ).

Fig. 2 Three dimensional FE model of mechanical deformation and evaluation for radial strength of the stent (unit: $\mathrm{mm}$ ).

Fig. 3 Schematic of three-point bending apparatus of the stent.

Fig. 4 Three dimensional model of three-point bending simulation (unit: $\mathrm{mm}$ ).

Fig. 5 PLLA tube samples cold-mounted in Polylactic Acid block used to tension tests at temperature $48^{\circ} \mathrm{C}$ (a) mounted sample of PLLA tube, (b) speckled sample before tension, (c) elongated sample after tension.

Fig. 6 Stress-strain curves of PLLA at $48^{\circ} \mathrm{C}$ and $37^{\circ} \mathrm{C}$.

Fig. 7 Simulation setup of the mechanical deformation and evaluation for stent radial strength of the PLLA stent. The deformation proceeded separately at $48^{\circ} \mathrm{C}$ and $37^{\circ} \mathrm{C}$. Two extra simulation steps as shown in the dashed box were on base of the mechanical deformation process for investigating the radial scaffolding properties.

Fig. 8 Three states during the simulation of three-point bending: (a) Original stent; (b) the end of Step 1; (c) the end of Step 2.

Fig. 9 Distribution of equivalent plastic strain in the stent crimped the OD to $2.60 \mathrm{~mm}$.

Fig. 10 Simulated and experimental profiles of stent crimped to the OD (a) $2.60 \mathrm{~mm}$; (b) 1.80 $\mathrm{mm}$ and (c) $1.41 \mathrm{~mm}$.

Fig. 11 Experimental and simulated profiles of different states during the stent expanding.

Fig. 12 Radial loading curve of the PLLA stent during expanding and unloading.

Fig. 13 Three-point bending force-deflection curve of the PLLA stent.

Fig. 14 Residual equivalent plastic strain distribution after three-point bending process.

Fig. 15 Initial (a) and optimized (b) structure configuration of the stent crimped to the outer 
diameter of $2.2 \mathrm{~mm}$ (the dimples were imposed on the convex side of the waved ring).

Fig. 16 Equivalent plastic strain of a) initial and b) optimized stents crimped to the OD of 2.2 $\mathrm{mm}$.

Fig. 17 Equivalent plastic strain of a) initial and b) optimized stents after spring-back with the expanded inner diameter of $3.1 \mathrm{~mm}$.

\section{Table captions:}

Table 1 Simulated radial recoil ratios of the stent after crimping and expanding

Table 2 Comparison of calculated results of PLLA stent with those reported by Schmidt et al. [22] 


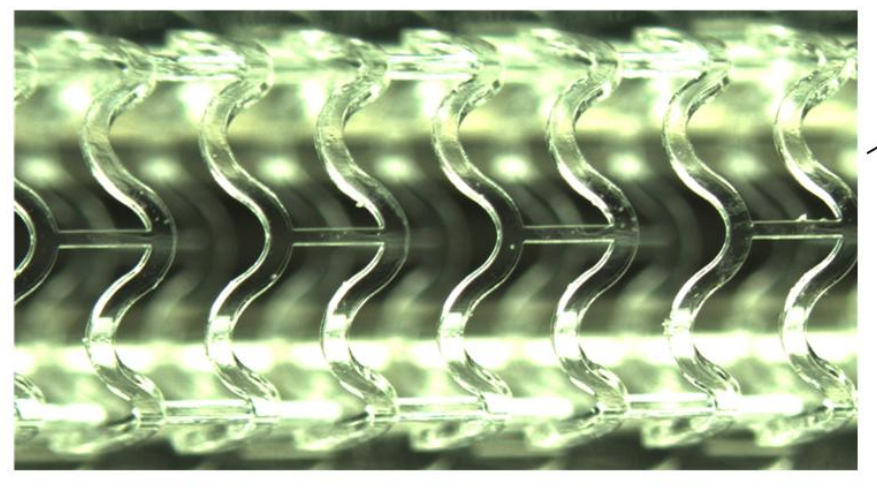

(a)

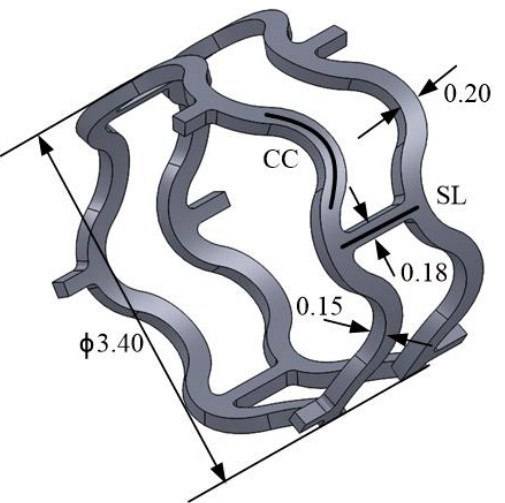

(b)

Fig. 1 PLLA stent (a) and geometry model (b) used for simulation and experiment (unit: mm). 


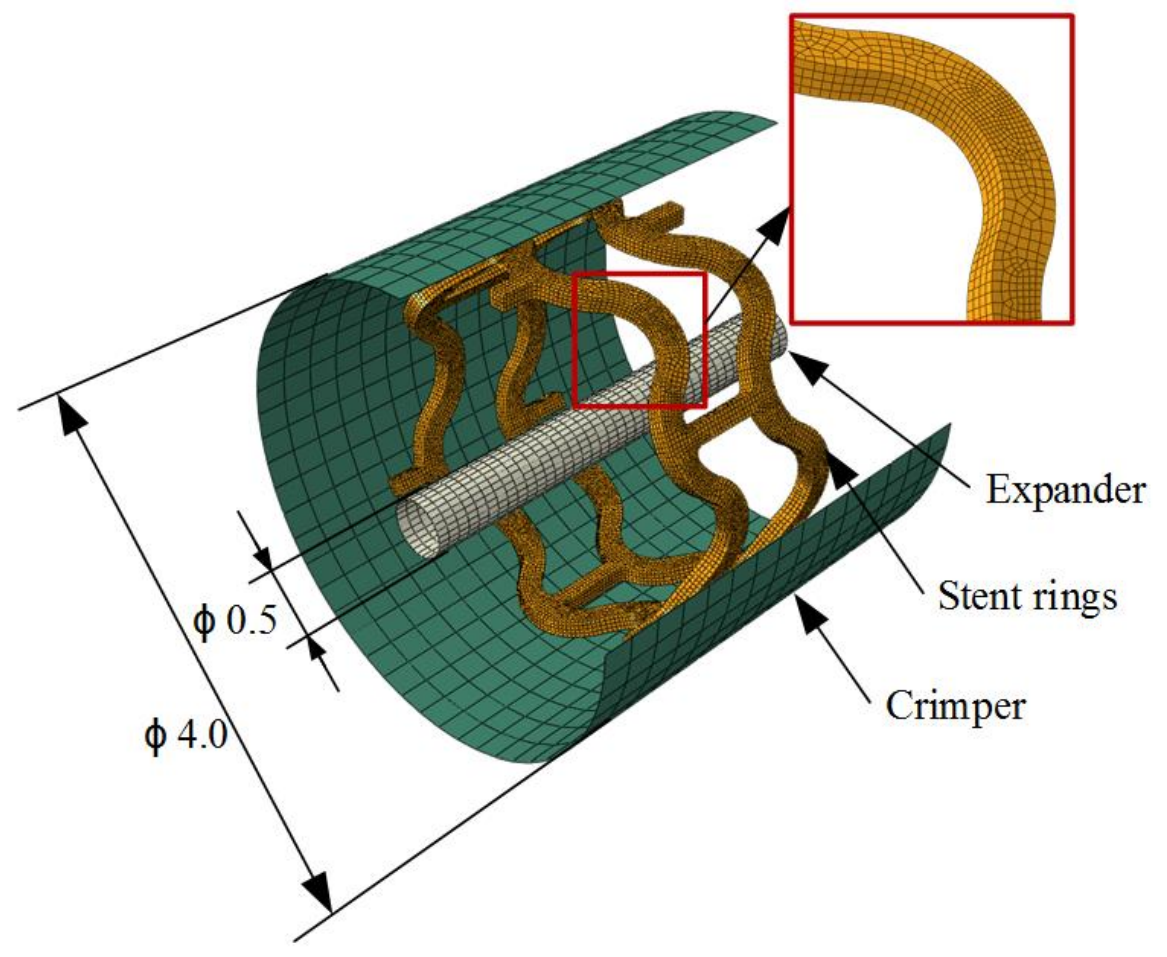

Fig. 2 Three dimensional FE model of mechanical deformation and evaluation for radial strength of the stent (unit: $\mathrm{mm}$ ). 


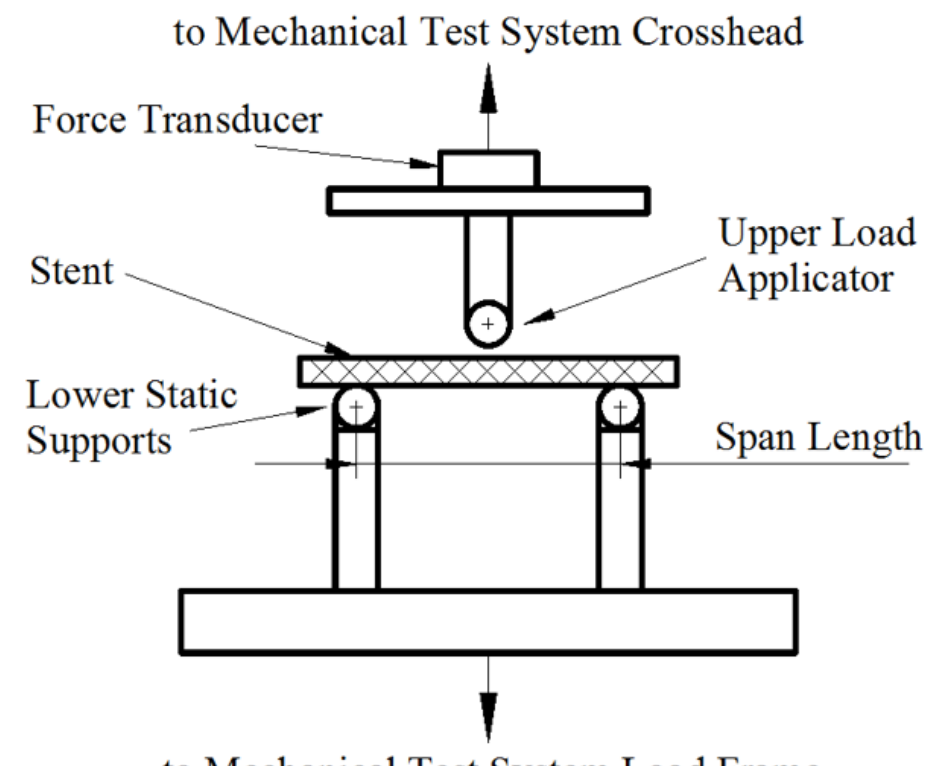

to Mechanical Test System Load Frame

Fig. 3 Schematic of three-point bending apparatus of the stent. 

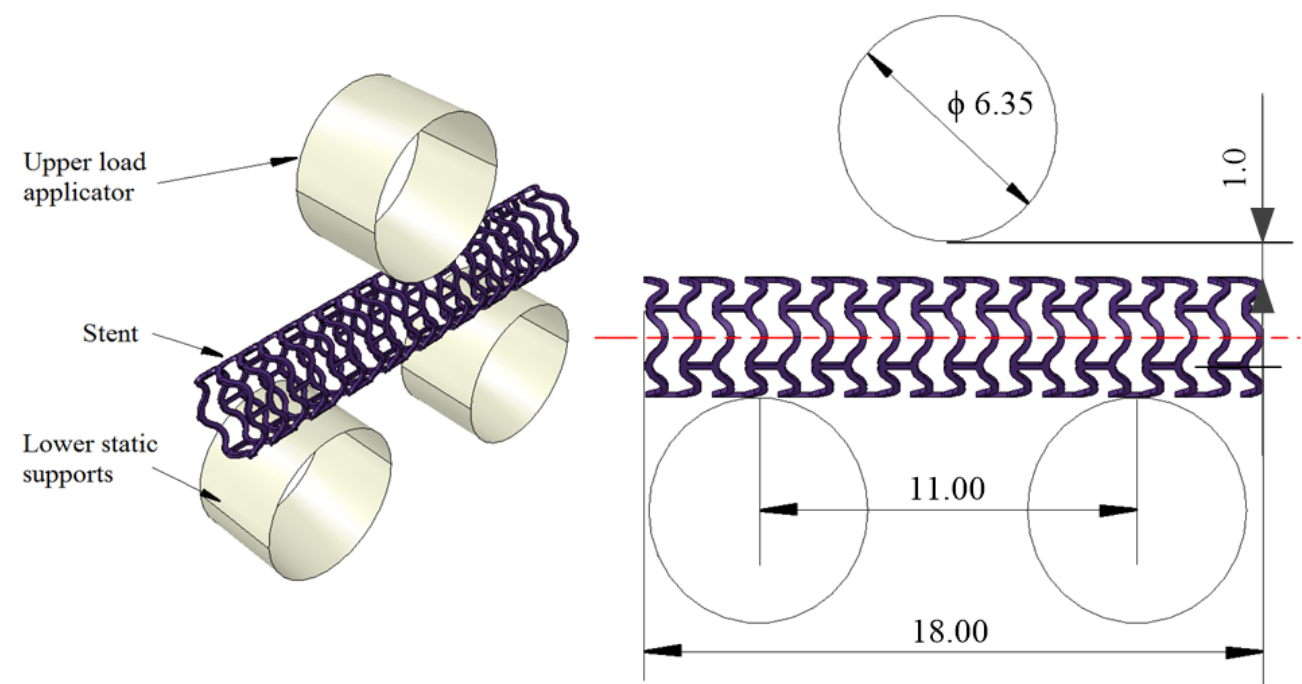

Fig. 4 Three dimensional model of three-point bending simulation (unit: $\mathrm{mm}$ ). 


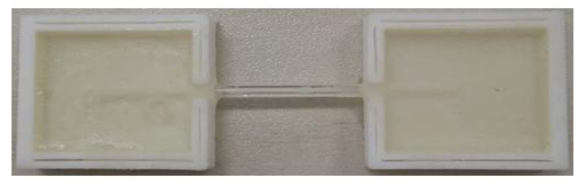

(a)

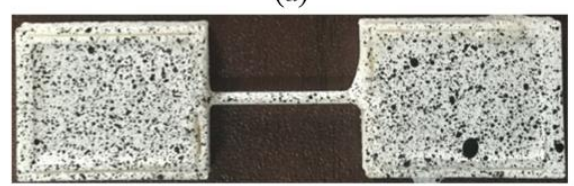

(b)

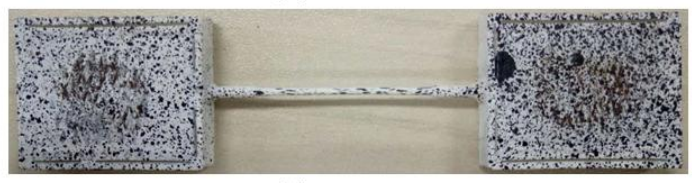

(c)

Fig. 5 PLLA tube samples cold-mounted in Polylactic Acid block used to tension tests at temperature $48^{\circ} \mathrm{C}$ (a) mounted sample of PLLA tube, (b) speckled sample before tension, (c) elongated sample after tension. 


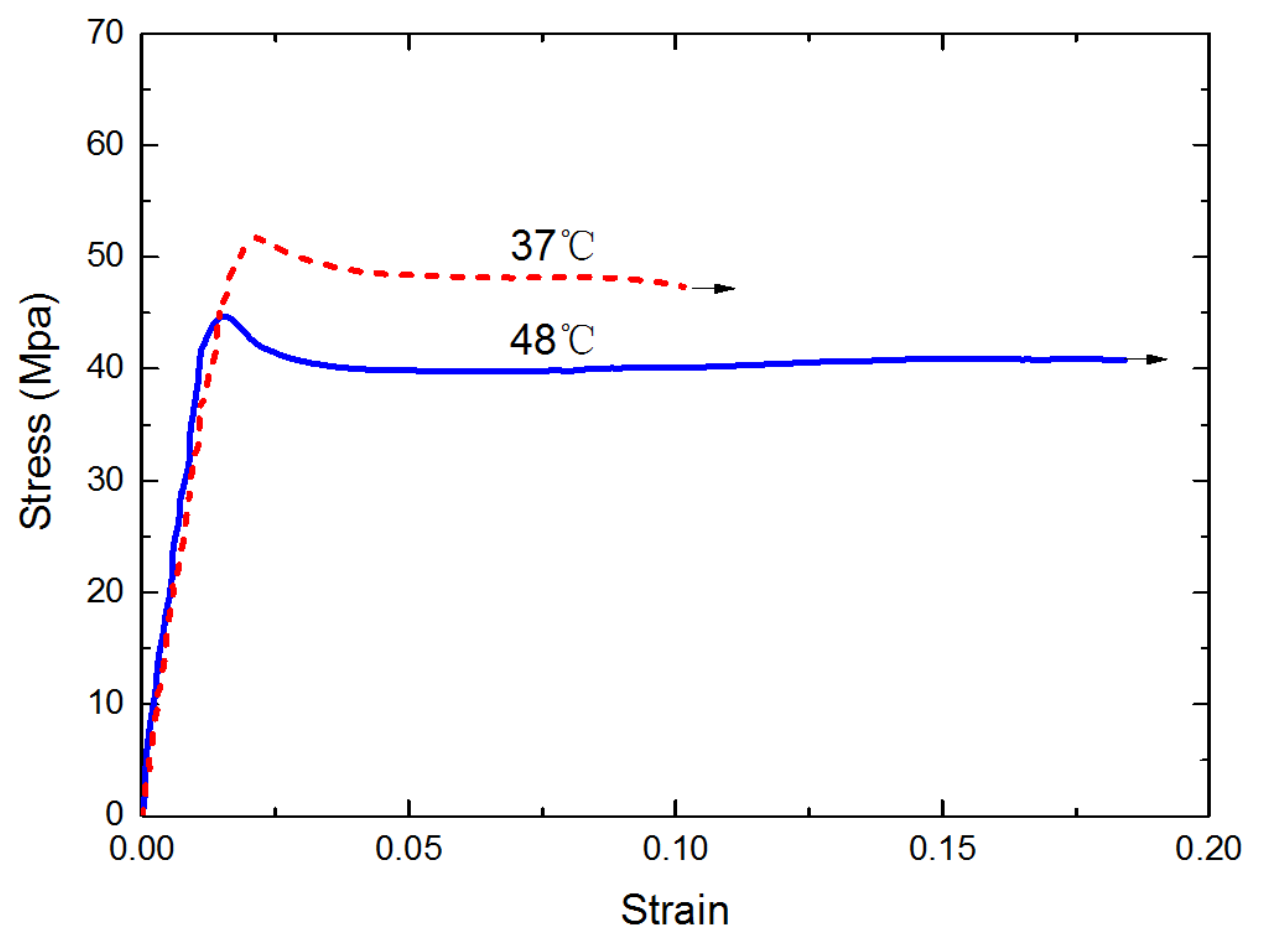

Fig. 6 Stress-strain curves of PLLA at $48^{\circ} \mathrm{C}$ and $37^{\circ} \mathrm{C}$. 


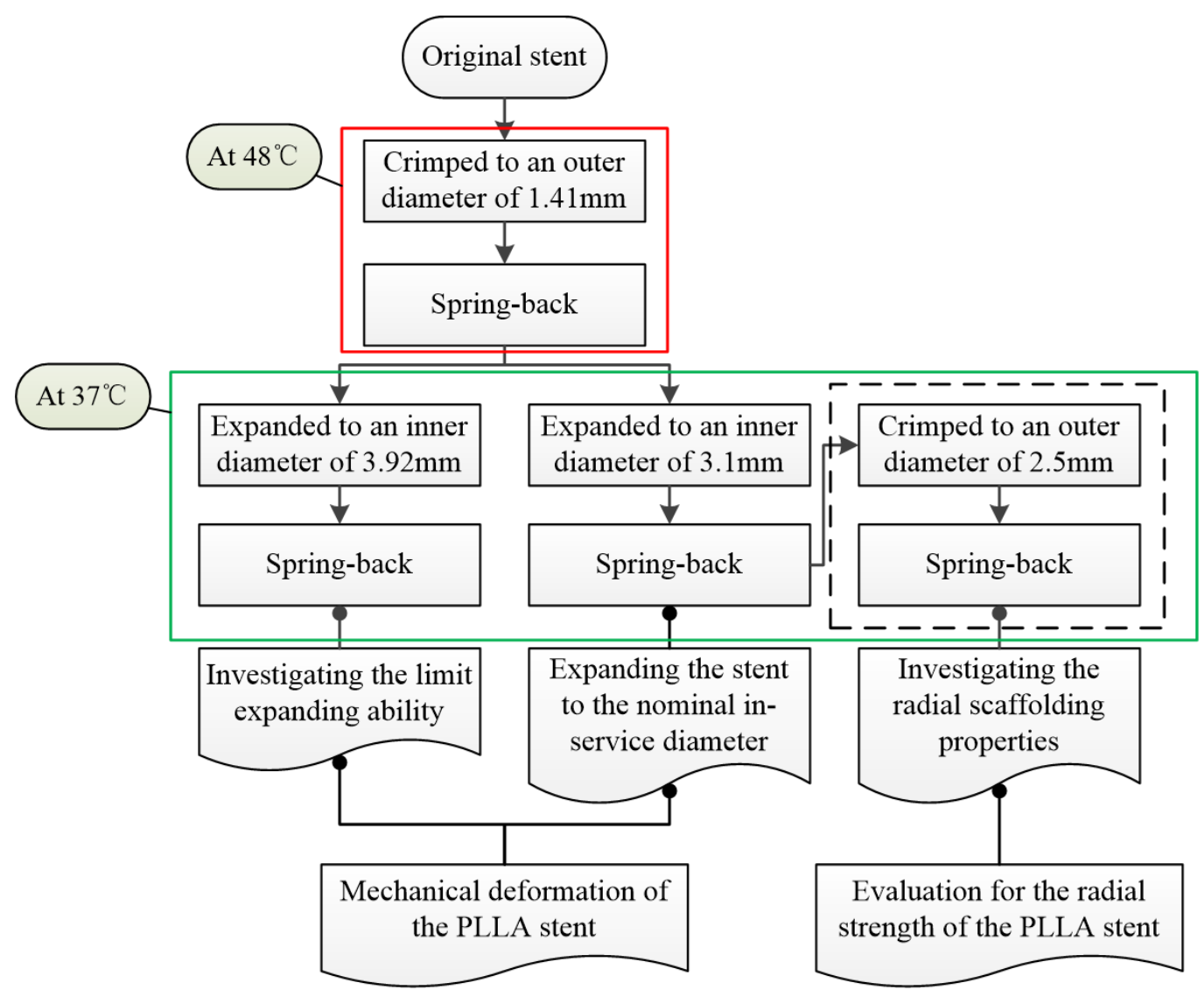

Fig. 7 Simulation setup of the mechanical deformation and evaluation for stent radial strength of the PLLA stent. The deformation proceeded separately at $48^{\circ} \mathrm{C}$ and $37^{\circ} \mathrm{C}$. Two extra simulation steps as shown in the dashed box were on base of the mechanical deformation process for investigating the radial scaffolding properties. 


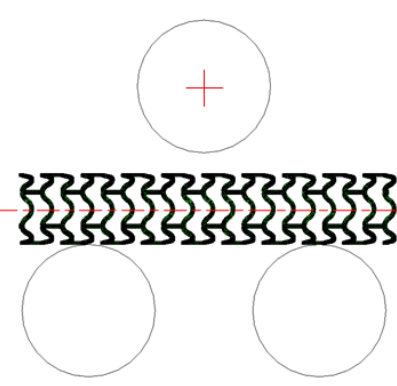

(a)
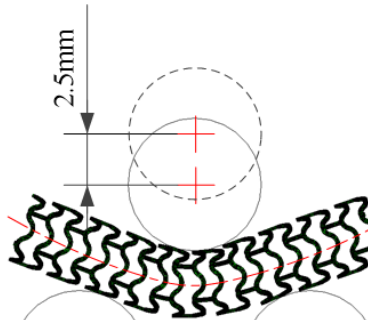

(b)

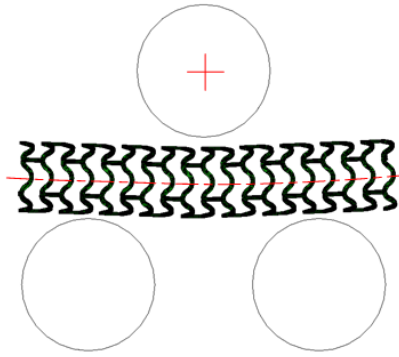

(c)

Fig. 8 Three states during the simulation of three-point bending: (a) Original stent; (b) the end of Step 1; (c) the end of Step 2. 


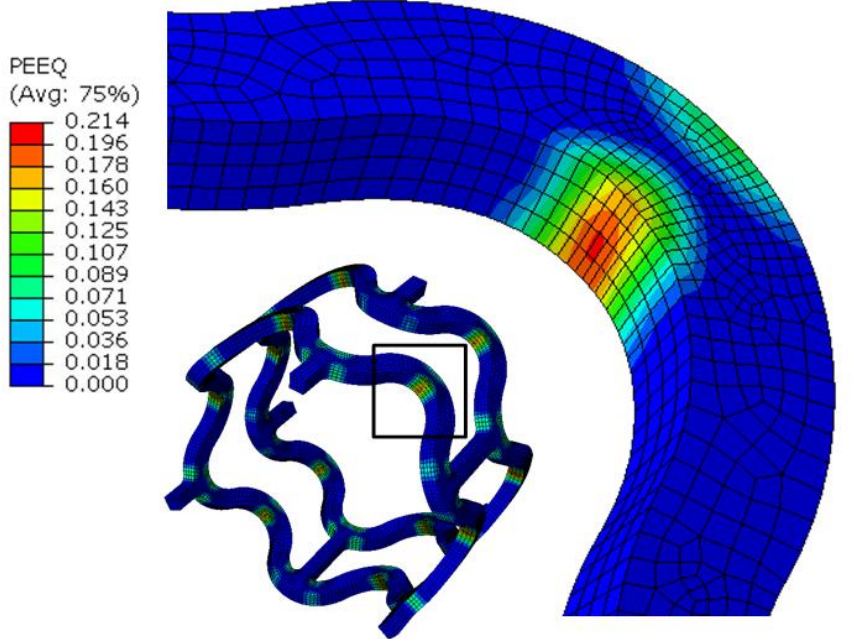

Fig. 9 Distribution of equivalent plastic strain in the stent crimped the OD to $2.60 \mathrm{~mm}$. 

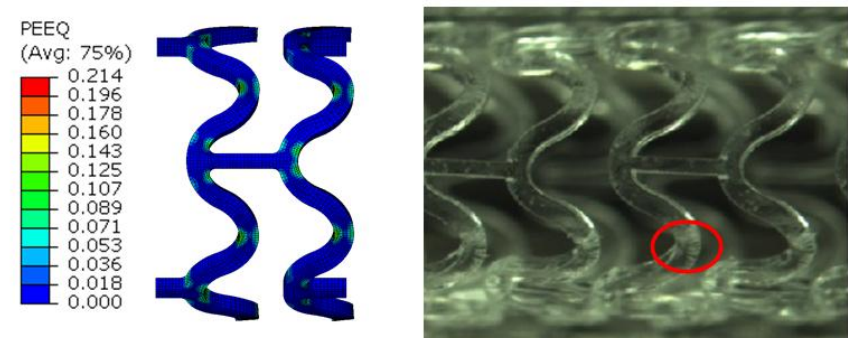

(a)
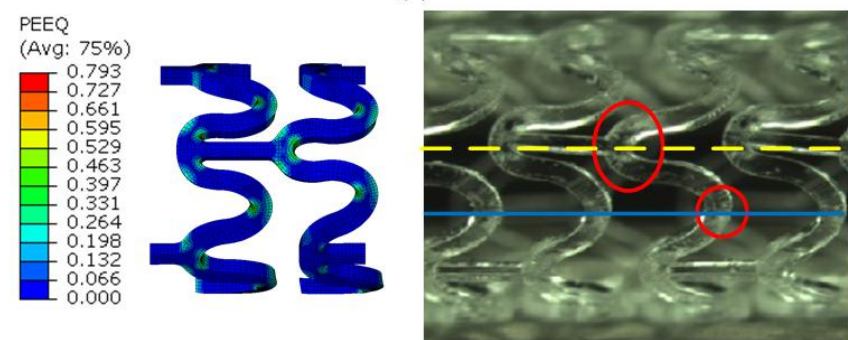

(b)
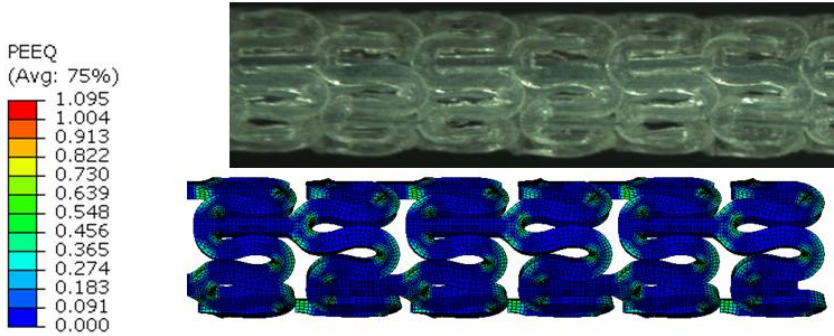

(c)

Fig. 10 Simulated and experimental profiles of stent crimped to the OD (a) $2.60 \mathrm{~mm}$; (b) 1.80 $\mathrm{mm}$ and (c) $1.41 \mathrm{~mm}$. 


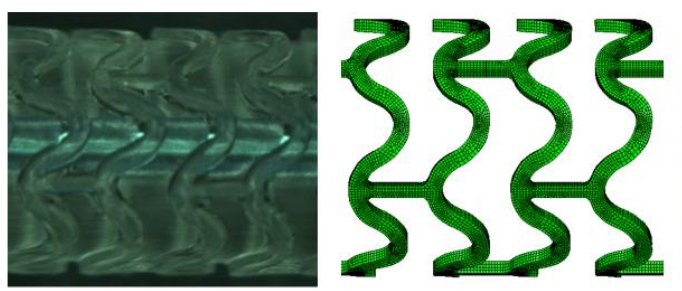

(a) $\mathrm{OD}=3.19 \mathrm{~mm}$

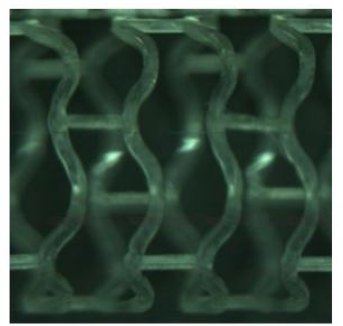

(c) $\mathrm{OD}=4.00 \mathrm{~mm}$

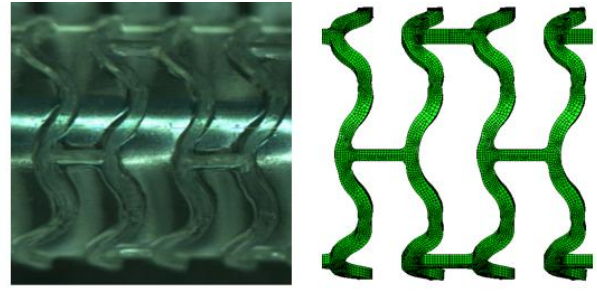

(b) $\mathrm{OD}=3.76 \mathrm{~mm}$

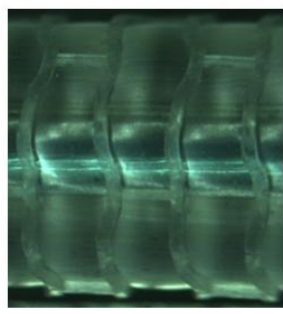

(d) $\mathrm{OD}=4.22 \mathrm{~mm}$

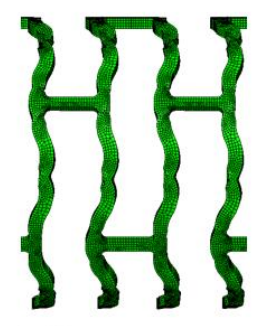

Fig. 11 Experimental and simulated profiles of different states during the stent expanding. 


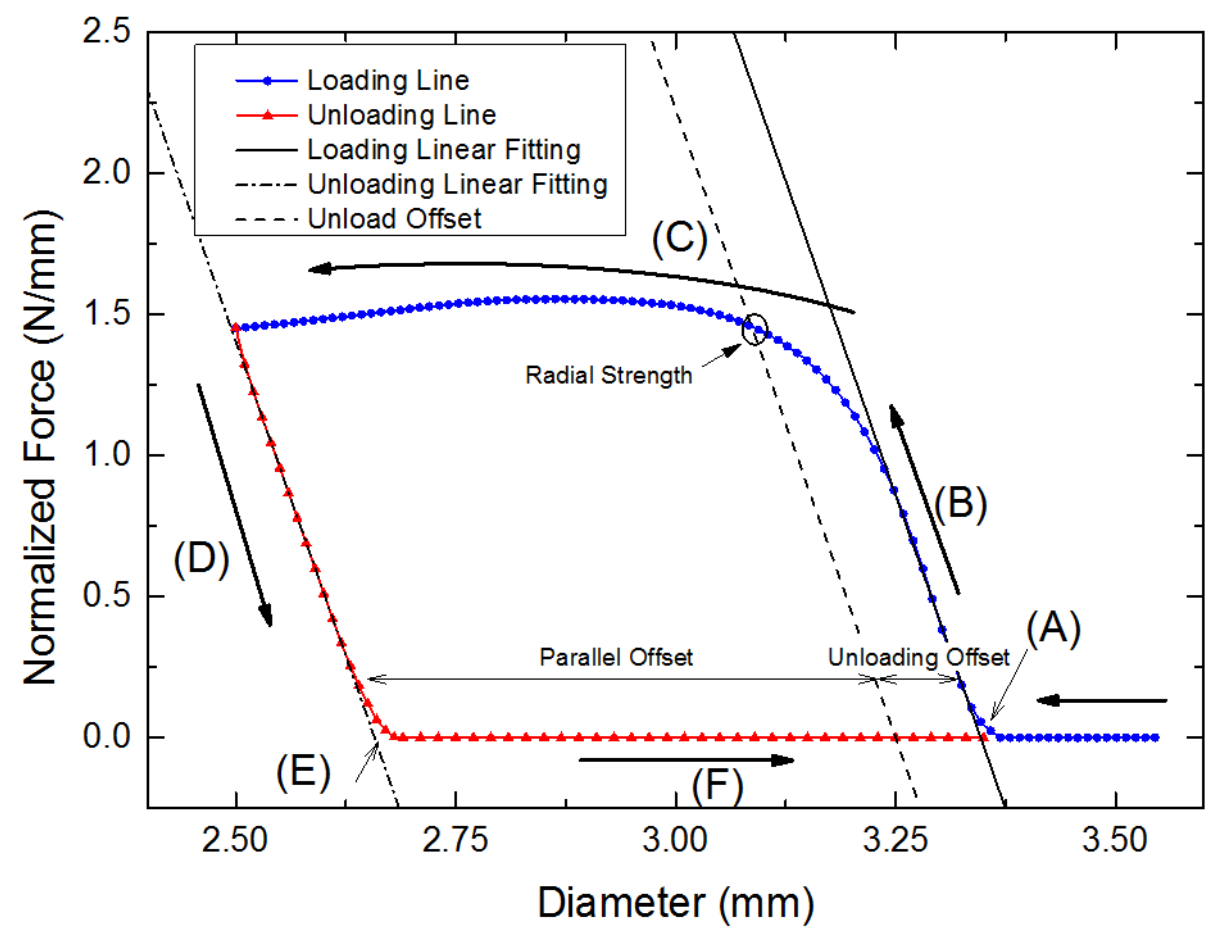

Fig. 12 Radial loading curve of the PLLA stent during expanding and unloading. 


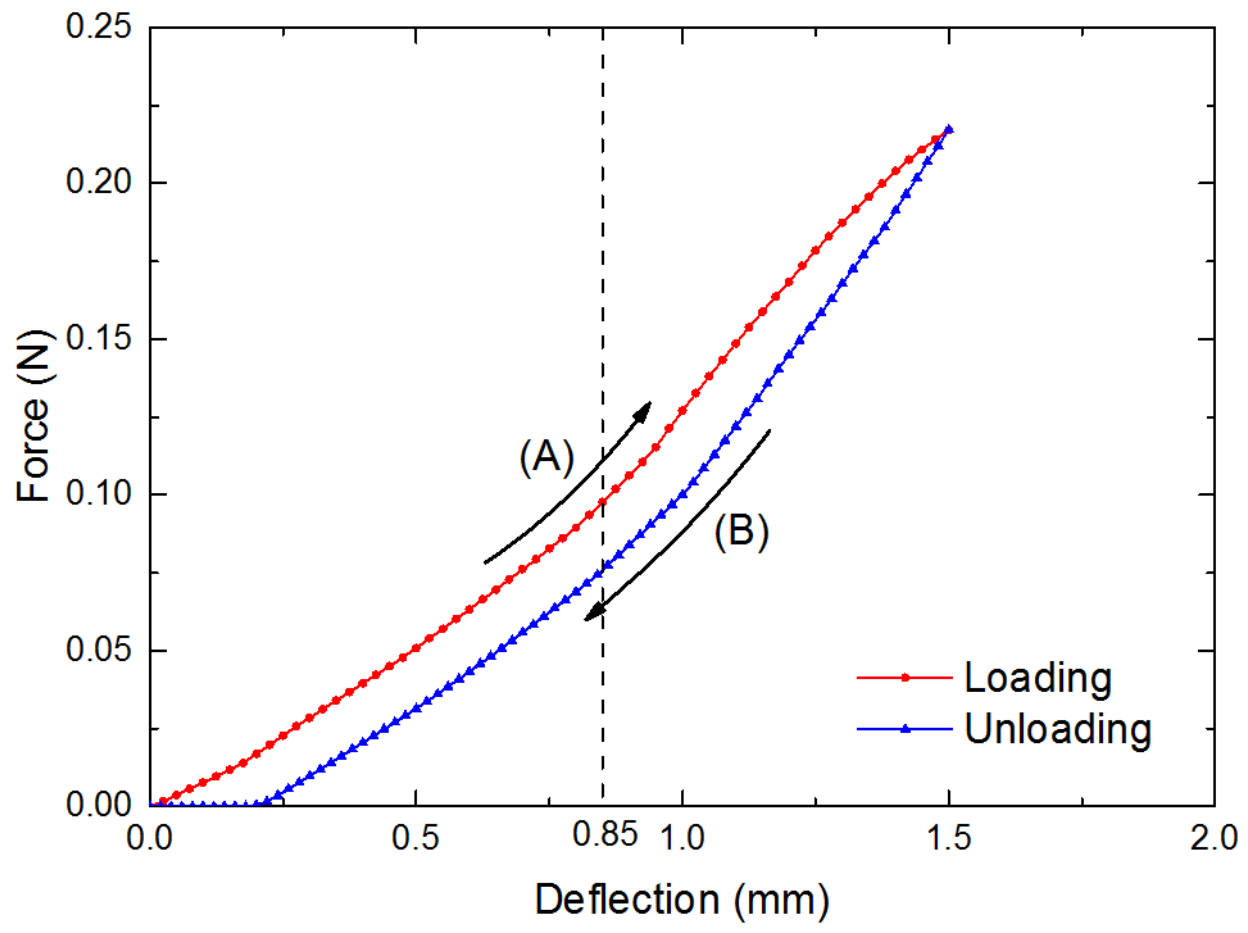

Fig. 13 Three-point bending force-deflection curve of the PLLA stent. 


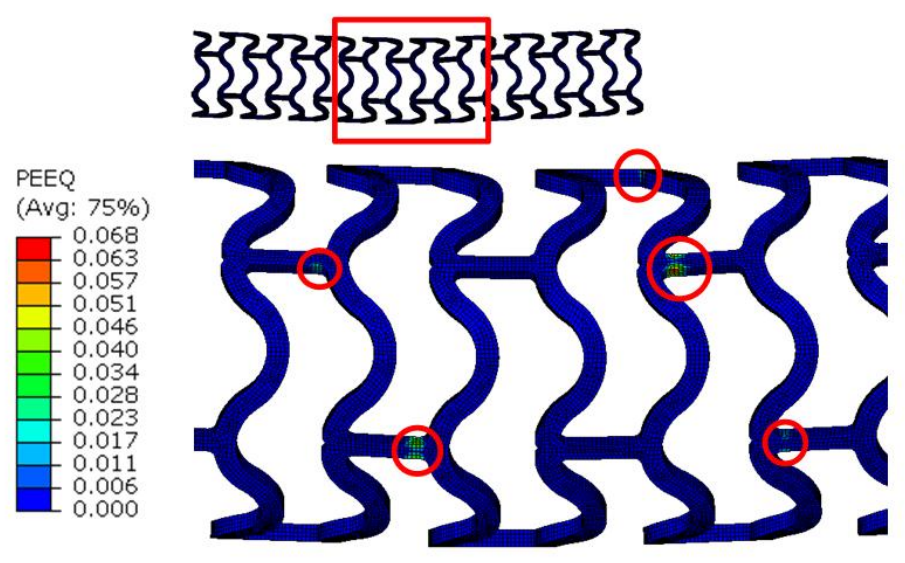

Fig. 14 Residual equivalent plastic strain distribution after three-point bending process. 


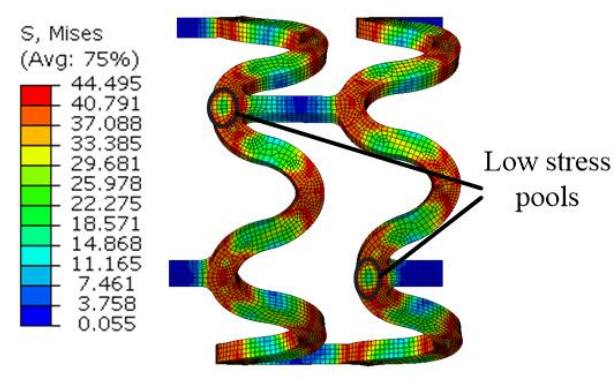

(a)

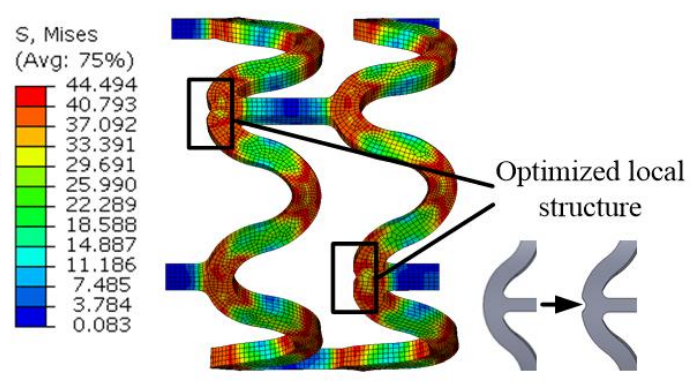

(b)

Fig. 15 Initial (a) and optimized (b) structure configuration of the stent crimped to the outer diameter of $2.2 \mathrm{~mm}$ (the dimples were imposed on the convex side of the waved ring). 


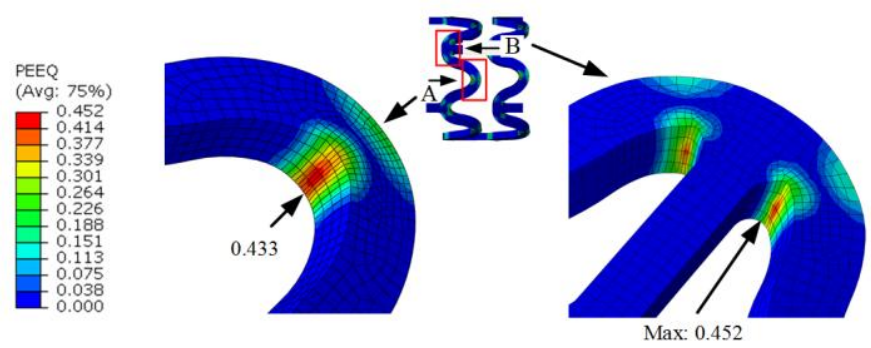

(a) Initial stent
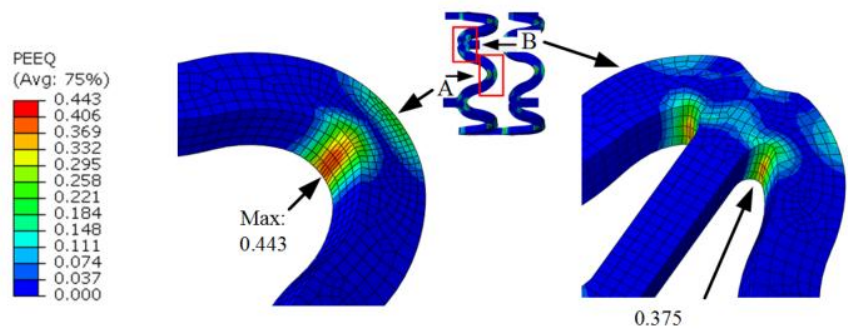

(b) Optimized stent

Fig. 16 Equivalent plastic strain of a) initial and b) optimized stents crimped to the OD of $2.2 \mathrm{~mm}$ 


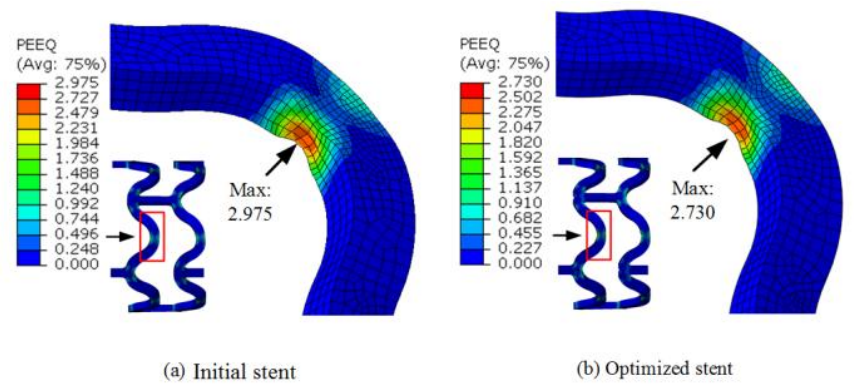

Fig. 17 Equivalent plastic strain of a) initial and b) optimized stents after spring-back with the expanded inner diameter of $3.1 \mathrm{~mm}$ 
Table 3 Simulated radial recoil ratios of the stent after crimping and expanding

\begin{tabular}{ccccc}
\hline \multirow{2}{*}{$\begin{array}{c}\text { Deformed dimension } \\
\text { of the stent }\end{array}$} & Crimped to OD (mm) & \multicolumn{2}{c}{ Expanded to ID (mm) } \\
\cline { 2 - 5 } & 1.41 & 3.10 & 3.70 & 3.92 \\
\hline Radial recoil ratio (\%) & 10.87 & 4.19 & 2.92 & 1.81 \\
\hline
\end{tabular}

Table 4 Comparison of calculated results of PLLA stent with those reported by Schmidt et al. [22]

\begin{tabular}{lcccc}
\hline & $\begin{array}{c}\text { Relaxed inner } \\
\text { diameter }(\mathrm{mm})\end{array}$ & $\begin{array}{c}\text { Expanding } \\
\text { radial recoil }(\%)\end{array}$ & $\begin{array}{c}\text { Collapse } \\
\text { pressure }(\mathrm{kPa})\end{array}$ & $\begin{array}{c}\text { Radial } \\
\text { stiffness }(\%)\end{array}$ \\
\hline The present model & 2.97 & 4.19 & 162 & 1.40 \\
Schmidt et al. [22] & $2.7 \sim 2.9$ & $3.60 \sim 6.87$ & $130 \sim 245$ & $0.51 \sim 3.99$ \\
\hline
\end{tabular}



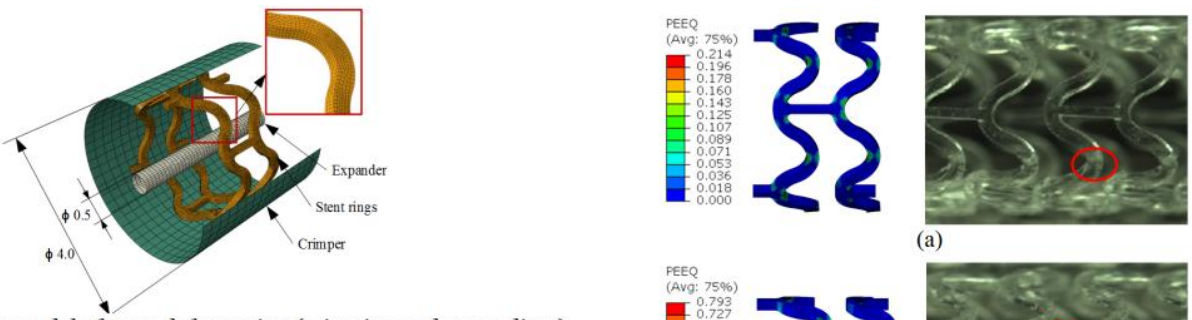

Finite element model of stent deformation (crimping and expanding )
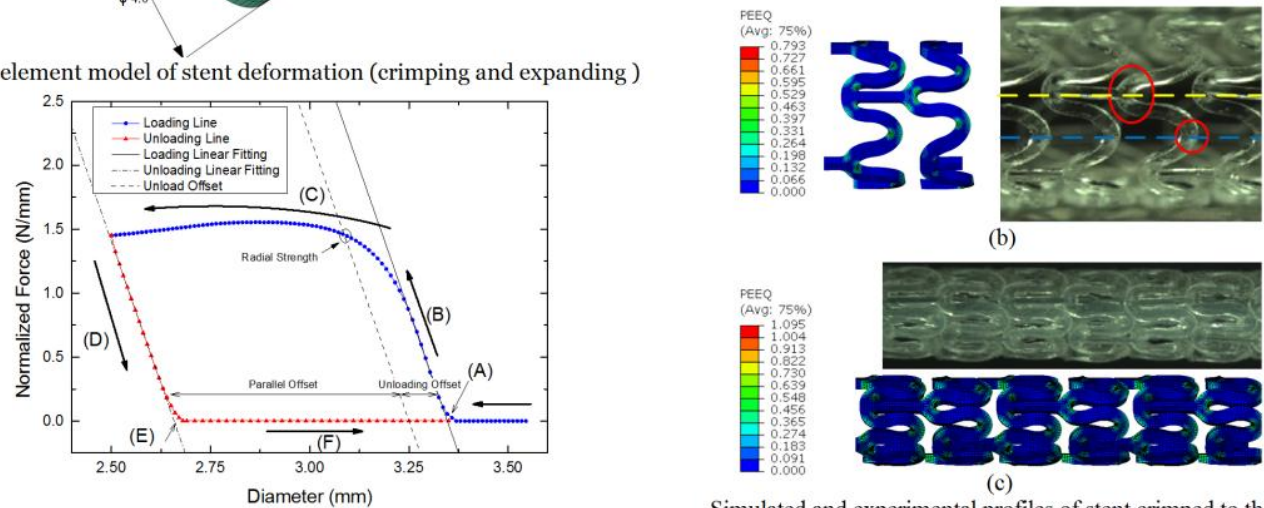

(b)

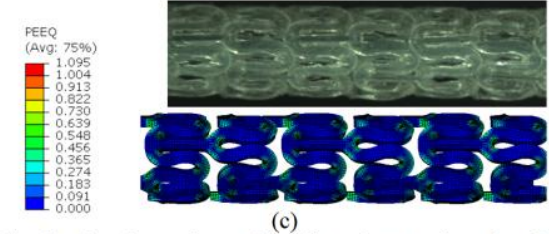

Simulated and experimental profiles of stent crimped to the OI (a) $2.60 \mathrm{~mm}$; (b) $1.80 \mathrm{~mm}$ and (c) $1.41 \mathrm{~mm}$. 